\title{
Exploring A New Mode of Urban Community Autonomy by Reconstructing the Cultural Memory
}

\author{
Zhao Junrong \\ The School of Public Management,Yunnan University of Finance and Economics, P.R.China 650221 \\ (zjrong7343@gmail.com)
}

\begin{abstract}
Absract
Community memoryis a kind of unique ideas and cognitive habits that formed inthe development of the community.Reconstructing community memory can form the residents' community identity. Based on analyzesof the Baiyunguan (a Taoist temple) community, the article shows the effects of reforming community memory for community autonomy.People can manage an urban community with historical tradition through a way of tapping its characteristic culture and stimulating people's sense of belonging.
\end{abstract}

Keywords:Community autonomy; Community memory; Community construction.

\section{Introduction}

In mainland China, community autonomy is the main orientation of community development. The government, academia and organizations at the grassroots level are committed to explore the right mainland Chinese community autonomy mode. Due to the differences between the area, community autonomy mode is also showing regional features. Many cities in China have a long history and rich culture, using of these historical culture may promote the development of community autonomy.

\section{Memory, collective memory and community memory}

The study of memory first appeared in the field of psychology, in order to explore the mysteries of the human beings (John R.Anderson, 1980). The first scholar to study the memory from a psychological point of view is Ebbinghaus, he published his research the memory in 1885 . The book describes the first accurate experiment about memory.

Early in 1925, French sociologists Maurice Halbwachs put forward the concept of collective memory, in his opinion, memory has the nature of collective. Personal memory, collective memory and historical memory are different (Maurice Halbwachs, 1925). Since the 1980s, the social circles and anthropology began widely noticed about the theory of collective memory.

In the study of the collective memory, some sociologists and anthropologists focus on these aspects: the first is to pay attention to the phenomenon of collective forget. Second, the relationship between imagine and historical memory handling. Others are theoretical discussion, such as the way of memory transmission.

In the The Temple of Memories: History, Power and Morality in a Chinese Village, Professor Jing Jun at Tsinghua University describes the reconstruction process of Confucius in some rural communities in northwest China, the purpose is "trying to understand how the history of a village influence the villagers' life" (Jing Jun, 1994). Taiwan's professor Wang Mingke explored the myth of Qiang ethnic group's society and history from the perspective of historical memory. Professor Huang Shumin did a research on people's memory in Lin village, Xiamen city in China. 
Under the influence of the collective memory theory, social circles appeared several other orientations: the research orientation of public memory, the research orientation of populace memory.

The core of the public memory study is national authority and the mainstream discourse. To sway people's collective memory means control people's impression, means that the legitimacy of state power is confirmed, so it is an important political issue, any kind of government will be committed to the public information dissemination system control. The research of populace memory is different, it emphasizes that some groups oppose and questioned the mainstream discourse in the society. The populace memory research is made up for the inadequacy of public memory research.

In China, Fei Xiaotong's doctoral dissertation Jiang Village Economy created a precedent in the local study of Chinese sociology. This paper is also the important work of study in the rural community. Represented by Fei Xiaotong, the first climax in the study of Chinese rural community memory started, the scholars studied Chinese local community by using the western theories. Since the 1980s, there is a group of young scholars began to pay close attention to the community development in the process of China's social transformation. He Xuefeng pointed out that the history of a village will affect the nature of the village, this is community memory ( $\mathrm{He}$ Xuefeng, 2000).

The above researches show that the community memory belongs to a kind of collective memory, it is a kind of unique ideas and cognitive habits that formed in the development of the community, it is a kind of cognitive activity, and also a kind of emotional experience. It contains the historical memory, social memory and cultural inheritance. Community memory is the connection to the residents' past and present, reconstructing community memory can form the residents' community identity.

\section{The influence of community memory}

Community autonomy means that the residents develop the community through the self management, self education, self service and self control by using the resources of the community itself in a democratic way (Wei Kenan, 2003). Community autonomy is the inevitable requirement of social development and democracy construction in China.

However, the current situation of the city community autonomy in China is: the participation of the residents' enthusiasm is not high, personnel type is narrow and they did little to community development. Someone has summarized the characteristics of the changes of Chinese community memory: the memory is becoming weak, the loss of memory pattern changed from passive to active, the impetus of memory changed from political power to market forces, and the function of community memory changed from identity to utility. Studies have pointed out that the loss of community memory makes the urban community lack of social resources.

So, the strength of the community memory directly affects the residents' sense of community, then the residents' sense of community affects people's action, and the action affects the integration of community resources and the process of community democratic construction. Reforming community memory can inspire the residents' feelings of belonging to their community, to mobilize them to participate in community construction, and then achieve the goal of community autonomy. 


\section{An example of Baiyunguan community}

Baiyunguan community located at Baiyunguan street, Xicheng district, Beijing, it is very typical and representative as a case to study the influence of community memory, it can help to find a new idea of community autonomy.

\subsection{The historical status of the Baiyunguan} community

Chinese Taoism is not only the important spiritual pillar of Chinese traditional society, but also an important part of the Chinese traditional culture. Baiyunguan temple is a Taoist temple, it was built in the tang dynasty, and is it the most prosperous place of Quanzhen Taoism. After the founding of new China, the Chinese Taoist association, Institute of Chinese Taoism culture and other organizations have successively set up there.

Whether the Taoism culture, or the existence of the temple, Baiyunguan temple has a very close relationship to the people's modern life there, it plays an important role in building a distinctive community:

Firstly, in a macro sense, Baiyunguan community belongs to the old down town, located in the core area, it has convenient transportation and abundant supplies, lit's the key point of urban planning. In the process of urban renewal, the city needs to rely on historical community to improve the cultural deposits, so this process will give the community residents with lots of employment opportunity.

Secondly, traditional culture will make the community groups to accept each other, reduce the gap between different classes of people, and enable them to unite.

Thirdly, people are more likely to accept history stories rather than the policy and theory, so reviewing the history, looking for a key figure in the community and explore community historical stories can change the residents' attitude toward the community.

\subsection{The present situation of the Baiyunguan community}

Modern Baiyunguan community has a population of more than 4000, among them the elderly accounted for $27 \%$. The feature of this community is many people in the community are opening stalls or shops around the Baiyunguan temple, they sell products, such as sacrifice, paper, or visit fortune-teller gold, fortune-telling and giving names. Their life and income depends on Baiyunguan temple and for the Taoist culture.

Baiyunguan community has a good external image, a large number of human resources and profound culture. The livelihood of the Taoist, five arts (music, chess, calligraphy, painting and tai chi), vegetarian diet, medical, and the tourism industry etc, all above these are bringing lots of benefits to the local residents.

Through interview and questionnaire survey we found that the local residents have these requirements: 1 , improve the hardware facilities and health conditions; 2, deepen the residents' culture understanding and belongings by enriching the connotation of the community culture; 3 , improve the enthusiasm of the residents, let them participate in activities.

\section{To explore the new mode of community autonomy}

Characteristics and needs of the community show that using of traditional cultural resources to create value and meeting the requirements of residents is a feasible way to promote community autonomy. 


\subsection{Arousing people's sense of belonging by reforming community memory}

Community belonging is a psychological state that the residents put themselves into a group or a place. This kind of mental state is a confirmation of the identity, and also the feeling of individual, including love, investment and attachment to the community. In the progress of community autonomy, many links cannot leave the community belonging, such as concept promotion, activity organization and resources allocation.

Memory is like an emotional bond, it connects people and communities. In today's changing society, the historic culture which is very different from the modern culture, it can make people no longer blundering, and have a good emotional experience.

In China, and even other countries in the world, there are a lot of communities like Baiyunguan community, they have a long history, very rich traditional culture and strong religious atmosphere. This kind of community must have created a common memory to the residents, especially the elderly, these memories can be thought of as a kind of emotional power of social reproduction, it can inspire people's feelings. Once the residents begin to curious about the history, they can easily focus on the community, then the cohesion of the community will be increased.

\subsection{Using incentive mechanism to promote residents' participation}

Incentive is one of the important methods of management. Internalization of community autonomy depends on the culture, but the externalization needs incentive.

American scholar Frederick Herzberg applied twofactor theory of incentive (Zhang Shu, 2002). He believes that there are two categories of factors associated with people's work enthusiasm: one is "incentive factors", such as promotion, recognition and honor, these factors can stimulate people's work motivation, let a person want to work consciously. Another one is "health factors", such as salary welfare, security, etc. Although these factors can not motivate people to work hard directly, they can prevent employees from discontent. These two factors can be used to set up the goal for the community residents, provide them with security, and create opportunities for them, encourage them to excavate and carry forward the traditional culture spirit, they will participate in the community management by themselves and realize the selfworth.

\subsection{The discussion of the new mode of community} autonomy

Based on the long-term observation and practice, for the community with traditional history and unique culture like Baiyunguan community, we can explore a new idea of community autonomy from the perspective of culture and emotion, that is: fully exploiting its peculiar historical and cultural resources, reforming the community cultural memory, let them see the charm and superiority of their community by connecting the history and people's emotions, then they will have more confidence to the community, love the community and contribute to the community development.

There are some methods here. First, interview with the old man in the community and record their stories through the way of oral, because oral history will reflect the value of community and people's emotional attitude. Second, explore and organize the local knowledge, including the material culture heritage like old buildings or cultural relics, the 
intangible cultural heritage like folk art, festivals, etiquette, etc. Show and promote these things to motivate and arouse the residents' social emotions and strengthen their understanding of the community. Third, organize activities based on the local characteristics, shape the unique style of the community, to make the residents feel a sense of pride and increase the cohesion of people.

\section{Conclusion}

In the process of the community autonomy construction and management for traditional urban community, the way of reforming the memory can be regarded as a targeted method.

Someone said that only culture is the greatest power to make people get together. Although the idea that using the cultural memory to let the residents participate in the community autonomy is still in the exploration, we believe that a community is incomplete without its culture; a community has no core spirit inside without its culture. Under the wave of globalization, in many of these similar cities, only the unique style and profound connotation community can be the place where people are willing to entrust a lifetime.

\section{Reference}

[1] He Xuefeng. Village Elite and Community Memory: Two-dimensional Framework of the Village [J]. Social Science Journal, 4, 2000.

[2] John R.Anderson. Cognitive Psychology and Its Implications $[\mathrm{M}]$. People's posts and telecommunications publishing house, 2012.

[3] Jing Jun. The Temple of Memories: history, power and Morality in a Chinese Village [M]. Fujian education press, 2013.

[4] Maurice Halbwachs. On Collective Memory [M]. Shanghai people's publishing house, 2002.

[5] Wei Kenan. The theory of community autonomy [J]. Journal of Sichuan University, 5, 2003.

[6] Zhang Shu. Administration of Social Work [M]. Social Sciences academic press, 2002. 